\section{Tumorigenesis in mice carrying a truncating Brca1 mutation}

\author{
Thomas Ludwig, ${ }^{1,6,7}$ Peter Fisher, ${ }^{2}$ \\ Shridar Ganesan, ${ }^{3}$ and Argiris Efstratiadis, 4,5,6,8 \\ ${ }^{1}$ Department of Anatomy and Cell Biology, and ${ }^{2}$ Department \\ of Pathology, Columbia University, New York, New York \\ 10032 USA; ${ }^{3}$ Dana-Farber Cancer Institute, Boston, \\ Massachusetts 02115 USA; ${ }^{4}$ Department of Genetics and \\ Development, and ${ }^{5}$ Institute of Cancer Genetics, Columbia \\ University, New York, New York, 10032 USA
}

We generated mouse mutants carrying in the Brca1 locus a modification $\left(\right.$ Brca1 $\left.^{\text {tr }}\right)$ that eliminates the C-terminal half of the protein product and obtained results indicating that, depending on genetic background, the missing BRCT and/or other domains are dispensable for survival, but essential for tumor suppression. Most of the apparently hypomorphic Brca1 ${ }^{\text {tr/tr }}$ mutants developed various tumors. Lymphomas were detected at all ages, whereas sarcomas and carcinomas, including breast cancer, appeared after a long latency. The mammary tumors showed striking variability in histopathological patterns suggesting stochastic engagement of tumorigenic pathways in their progression, to which the Brca1 $^{\text {tr/tr }}$ mutation was apparently a late participant.

Received January 16, 2001; revised version accepted March 15,2001

The human breast cancer susceptibility gene BRCA1 (for review, see Scully and Livingston 2000; Welcsh et al. 2000) encodes predominantly a nuclear phosphoprotein of 1863 amino acids (shorter isoforms, some of them confined to the cytoplasm, are translated from minor mRNA species). With the exception of a RING finger domain located at the N-terminal region and two BRCT domains that are proximal to the $\mathrm{C}$ terminus, no other motifs have been recognized. Nevertheless, direct or indirect interactions of unknown physiological significance between BRCA1 segments and various other proteins have been revealed using cell lines or in vitro conditions. Some of these experiments suggested that the C-terminal region of BRCA1 acts as a transactivator (for review, see Monteiro 2000), whereas other data implied that BRCA1 is involved in the maintenance of genomic integrity (see Scully and Livingston 2000). It remains unknown, however, how ablation of BRCA1 function contributes to the pathogenesis of breast cancer.

Initial attempts to generate animal models of BRCA1associated breast cancer were unsuccessful, as knockouts of the Brca1 murine homolog (1812 amino acids;

[Key Words: Brca1; mouse mutant; mammary tumors] ${ }^{6}$ Corresponding authors.

${ }^{7}$ E-MAIL t154@columbia.edu; FAX (212) 304-7158.

${ }^{8}$ E-MAIL arg@cuccfa.ccc.columbia.edu; FAX (212) 304-7158.

Article and publication are at www.genesdev.org/cgi/doi/10.1101/ gad.879201.
$58 \%$ human-mouse homology) resulted in embryonic lethality of nullizygous embryos, whereas heterozygous mice did not develop mammary or other tumors (for review, see Deng and Scott 2000; for conditional mutants, see Results and Discussion). In contrast with mutant mice, a patient with breast cancer has been described (Boyd et al. 1995) with inherited homozygosity for a frameshift mutation potentially generating a truncated protein of 900 amino acids (deletion of two A residues and appearance of a stop codon at positions 2800 and 2820 , respectively, of the BRCA1 cDNA sequence). Considering that none of the described Brcal nullizygous mice could synthesize a truncated Brcal peptide with sufficient length for nuclear localization, it was still possible to postulate that the domains remaining on a truncated 900-residue BRCA1 protein could be sufficient, if stable, to sustain embryonic development in both humans and mice. To test this hypothesis, we modified the Brca1 locus in mice by mimicking the human $\mathrm{AA}_{2800}$ mutation. Here, we show that the mutant mice, which are viable in particular genetic backgrounds, develop a variety of tumors, including breast cancer.

\section{Results and Discussion}

\section{Gene targeting and breeding of mutants}

A mutant allele, designated Brca1 ${ }^{\text {tr }}$, was generated by introducing with a two-step knock-in targeting approach a 50-bp insertion into exon 11 of a Brcal locus in mouse $129 /$ Sv embryonic stem (ES) cells (see Fig. 1A-C). The Brcal $^{\text {tr/+ }}$ heterozygous progeny of transmitting male chimeras mated with C57BL/6J females were phenotypically normal and were intercrossed to generate Brca1 ${ }^{\text {tr/tr }}$ homozygous mutants (Fig. 1D).

The modification of the Brcal ${ }^{\text {tr }}$ allele was verified by sequencing cloned PCR products (Fig. 1B). Moreover, as shown by sequencing RT-PCR products derived from mutant RNA templates, the insertional mutation did not result in splicing abnormalities. The mutation resulted in a frameshift and in the appearance of a stop codon expected to lead to truncation of the protein product after the first 924 amino acids (Fig. 1B). Therefore, it was not surprising to observe by Northern analysis of embryonic RNA that, because of nonsense-mediated mRNA decay, the mutant transcript (practically indistinguishable in size from wild type; $\sim 7.2 \mathrm{~kb}$ ) was significantly reduced in amount in comparison with the controls (Fig. 1E). In contrast, the amount of a splicing variant lacking exon $11(\Delta 11,3.9 \mathrm{~kb})$, which is normally approximately fivefold less abundant than the fulllength transcript (Mixon et al. 2000), was maintained at approximately wild-type levels (not shown). However, the short cytoplasmic Brcal isoform lacking nuclear localization signals that is encoded by $\Delta 11$ cannot sustain by itself viability beyond embryonic day 18.5 (see Deng and Scott 2000).

Despite several attempts, it was impossible to visualize the presence of truncated Brcal, because the only available antibody (rabbit polyclonal B28) recognizing the $\mathrm{N}$-terminal region of the protein generated extremely high background upon immunoblotting. However, using a monoclonal antibody (GH118) recognizing the C-terminal region of Brcal, we showed by Western analysis 
A
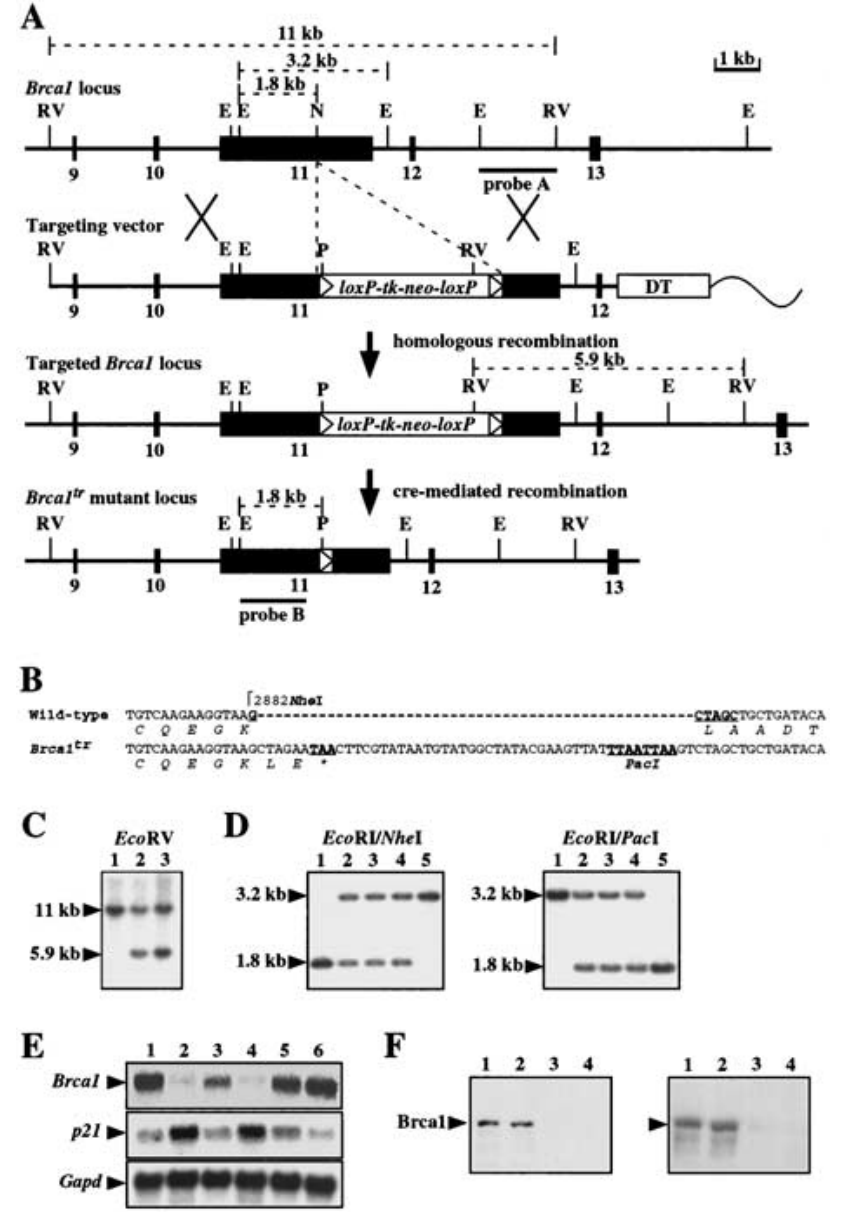

$\mathbf{F}$
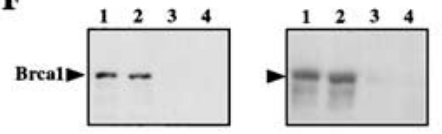

Figure 1. Generation of Brca1 hypomorphic mouse mutants. $(A)$ Targeting scheme. A partial restriction map (exons 9-13; black rectangles) of the Brca1 locus is shown on top, followed by a diagram of the targeting vector used to insert a $t k-n e o$ cassette flanked by lox $P$ sites (open triangles; not to scale) into a unique NheI site of exon 11 by homologous recombination (large X symbols). An open rectangle and a wavy line represent a diptheria toxin gene (DT) and the plasmid vector. The tk-neo cassette was removed by transient expression of cre in targeted embryonic stem (ES) cells (generation of a $B_{r c a 1}{ }^{\text {tr }}$ allele carrying a single loxP site insert). (E) EcoRI; (RV) EcoRV; (N) NheI; (P) PacI. The positions of the probes used for Southern analyses and the sizes of the endogenous and targeted DNA fragments recognized by these probes are shown. $(B)$ Structure of exon 11 in the region of insertion in Brca1 $1^{t r}$ as determined by DNA sequencing of PCR and RT-PCR products (the NheI site at position 2882 was destroyed, whereas a PacI site was introduced in the mutant allele). The appearance of a stop codon (TAA; asterisk) in the Brca $^{\text {tr }}$ sequence is shown. $(C)$ Southern analysis of ES cell DNA digested with EcoRV, to confirm the initial targeting. Because of introduction of an additional EcoRV site by the inserted cassette, the 11-kb EcoRV wild-type fragment detected by probe A (lane 1) is reduced to $5.9 \mathrm{~kb}$ in targeted ES clones (lanes 2,3). (D) Genotyping by Southern analysis with probe B by using tail DNA digested with EcoRI/NheI (left) or EcoRI/PacI (right) from wild-type (lane 1), Brcal $^{\text {tr/+ }}$ heterozygous (lanes 2-4), and Brca ${ }^{\text {tr/tr }}$ homozygous (lane 5) mice. (E) Northern analysis of total RNA (15 $\mu \mathrm{g}$ per lane) from e11.5 wild-type (lanes 1,6), $\mathrm{BrCa}^{\text {tr/+ }}$ heterozygous (lanes 3,5), and Brca ${ }^{\text {tr/tr }}$ homozygous (lanes 2,4) embryos. The blot was hybridized sequentially (after stripping) with cDNA probes for Brca1, p21 Waf1, and Gapd (loading control). (F) Western analysis to assay for the presence of Brcal in protein extracts from wild-type (lanes 1,2) and Brca ${ }^{t r / t r}$ homozygous mutant (lanes 3,4) embryos by using monoclonal GH118 either directly (left) or after immunoprecipitation with the polyclonal antibody B28 (right; see Materials and Methods). either directly or after immunoprecipitation with B28 that, in contrast with wild-type controls, full-length Brcal was absent from protein extracts of mutant embryos (Fig. 1F).

Breeding of $\mathrm{Brca1}^{\text {tr/+ }}$ heterozygotes indicated that survival of Brca1 ${ }^{\text {tr/tr }}$ homozygous mutants depended on genetic background (details of an extensive genetic analysis with complete data presentation will be published elsewhere; in prep). Of the progeny that came to term from matings between 129/Sv $\times$ C57BL/6J heterozygous hybrids, only $\sim 4 \%$ were homozygous Brca1 ${ }^{\text {tr } / t r}$ mutants. This significant deviation from the expected mendelian frequency $(25 \%)$, which was aggravated further by backcrossing with C57BL/6J mice, was the consequence of a high incidence of embryonic lethality associated with developmental abnormalities and growth retardation. The latter was previously correlated in Brca1 nullizygotes with hypoproliferation and increase in the expression of $p 21^{\text {Waf1 }}$, a p53 target gene (Hakem et al. 1996). A similar increase of $p 21^{\text {Waf } 1}$ transcripts was observed in Brca1 $^{\text {tr/tr }}$ embryos in comparison with controls (Fig. 1E). Interestingly, rescue from lethality and complete restoration of mendelian ratios was observed by backcrossing with $129 / \mathrm{Sv}$ animals (several rounds) or by outcrossing using the MF1 strain of mice. The survivors manifested mild growth retardation, kinky tails, skin pigmentation defects, and male (but not female) infertility due to arrested spermatogenesis.

It remains to be seen whether different Brcal domains are involved in mechanistically different functions. Clearly, Brcal is indispensable for early embryos and plays other developmental roles revealed in hypomorphic mutants. Interestingly, in the absence of adverse strain modifiers, the C-terminal half of the protein is dispensable for viability, but crucial for a gender-specific meiotic role and for tumor suppression (see below).

\section{Brca $1^{\text {tr/tr }}$ mutants develop a variety of tumors}

Monitoring of a cohort of viable Brca1 $^{\text {tr/tr }}$ mutants showed that tumors appeared in 76 of 89 mice $(\sim 85 \%)$, which died or were killed when moribund. Kaplan-Meier cumulative survival curves (not shown) indicated that the time of median tumor-free survival $\left(\mathrm{T}_{50}\right)$ was $\sim 1.4$ years. During the same time period, only seven of 27 control animals $(26 \%)$ died of spontaneous tumors that appeared at a very progressed age. The difference was statistically highly significant $(P<0.0001)$ indicating that the Brca1 ${ }^{\text {tr/tr }}$ mutation participated in tumorigenesis. Sex had no influence on tumor incidence or survival time. Most of the animals with tumors (83\%) had a genetic background enriched in MF1 strain component. Because only a few survivors with different backgrounds were monitored, potential strain effects on latency were not analyzed (the data on tumorigenesis are presented altogether, as significant statistical bias could not be introduced).

Overall, 92 tumors were encountered in the mutants (60 animals had a single tumor, and 16 animals had two tumors; Table 1). The tumor spectrum included lymphomas, sarcomas, adenomas/carcinomas, and other types. Interestingly, lymphomas appeared at any age between 1 and 24 mo, whereas nonlymphoid tumors started appearing in animals older than 9 mo (there was also a significant difference between average latencies; $\mathrm{T}_{50}$ of $\sim 14 \mathrm{vs}$. $18 \mathrm{mo})$. 
Ludwig et al.

Table 1. Tumor spectra

\begin{tabular}{|c|c|c|}
\hline Brcal $^{t r / t r}$ & $\mathrm{Brcal}^{t r / t r} /{\mathrm{p} 53^{-/-}}^{-1}$ & $\mathrm{Brcal}^{\mathrm{tr} / \mathrm{tr}} / \mathrm{p} 53^{+/-}$ \\
\hline 92 tumors (76 mice) & 9 tumors (8 mice) & 8 tumors (7 mice) \\
\hline $\begin{array}{l}32 \text { lymphomas }(35 \%) \\
19 \text { mediastinal } \\
12 \text { nodal } \\
1 \text { thymic }\end{array}$ & 8 lymphomas (89\%) & 3 lymphomas (37\%) \\
\hline $\begin{array}{l}10 \text { Sarcomas }(11 \%) \\
2 \text { angiosarcomas } \\
8 \text { spindle cell sarcomas } \\
7 \text { retroperitoneal } \\
1 \text { dermal }\end{array}$ & $\begin{array}{l}1 \text { sarcoma }(11 \%) \\
\text { Angiosarcoma }\end{array}$ & $\begin{array}{c}1 \text { sarcoma }(13 \%) \\
\text { Osteosarcoma }\end{array}$ \\
\hline $\begin{array}{l}41 \text { adenomas/carcinomas }(44 \%) \\
12 \text { breast } \\
13 \text { lung } \\
13 \text { liver } \\
2 \text { uterus } \\
1 \text { colon }\end{array}$ & & $\begin{array}{l}3 \text { adenomas/carcinomas }(37 \%) \\
2 \text { breast } \\
1 \text { lung }\end{array}$ \\
\hline $\begin{array}{l}9 \text { other tumor types }(10 \%) \\
4 \text { undifferentiated } \\
4 \text { hemangiomas } \\
1 \text { ovarian teratoma }\end{array}$ & & $\begin{array}{l}1 \text { other type (13\%) } \\
\text { Angiopericytoma }\end{array}$ \\
\hline
\end{tabular}

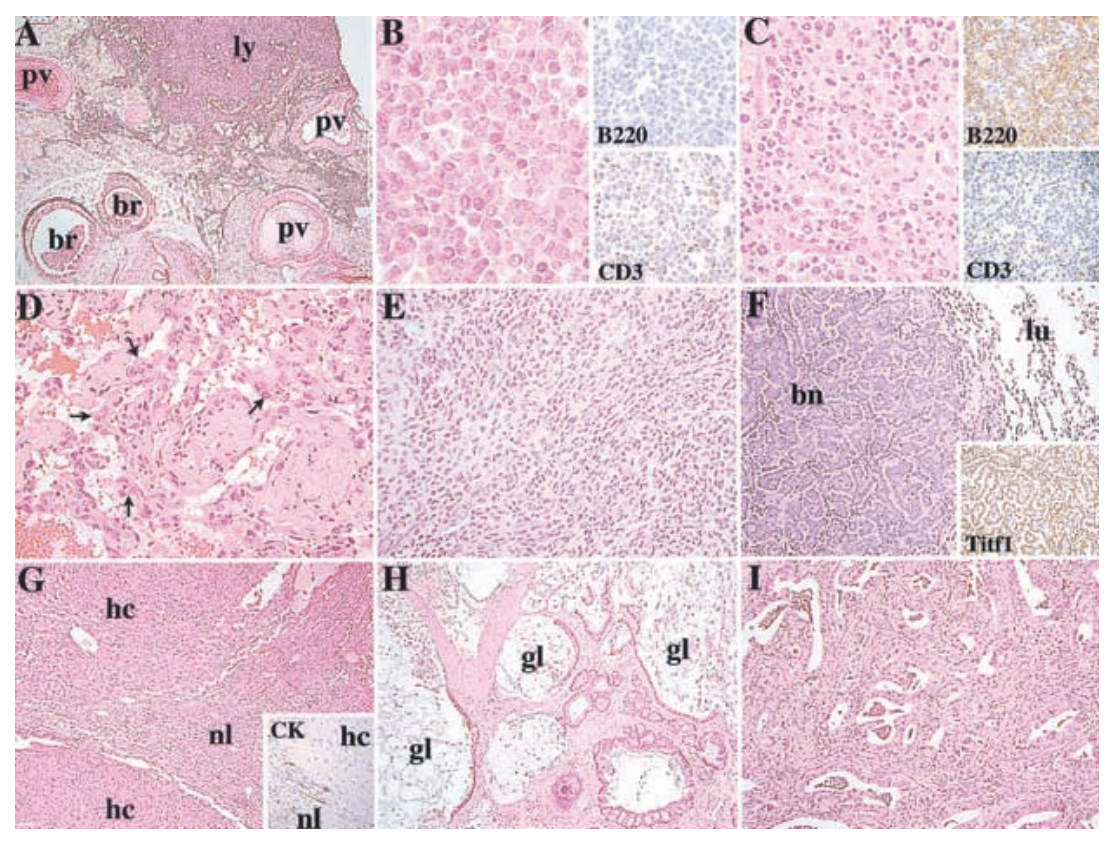

Figure 2. Brca1 $1^{\text {tr } / \text { tr }}$ mutants develop a variety of tumors. $(A-I)$ Examples of histological sections from nonmammary neoplasms are shown. (A) Mediastinal lymphoma (ly) invading soft tissues around pulmonary bronchi (br) and pulmonary vessels (pv). (B) The same lymphoma as in $(A)$ shown at higher magnification. (insets) The immunophenotype of the tumor is $\mathrm{B}^{2} 20^{-}$and $\mathrm{CD}^{+}$(brown staining) and therefore of T-cell origin. $(C)$ Nodal B cell lymphoma $\left({\mathrm{B} 220^{+}}\right.$and $\mathrm{CD}^{-}$; insets). (D) Angiosarcoma with atypical endothelial cells (arrows) lining anastomosing vascular channels. (E) Spindle cell sarcoma (retroperitoneal). (F) Bronchioloalveolar neoplasm (bn). The interface with normal lung tissue (lu) is shown. Positive nuclear immunostaining for Titf1 (thyroid transcription factor 1; inset) confirms that the tumor is of primary lung origin. $(G)$ Nodules of hepatocellular carcinoma (hc) lacking bile ductular epithelium and therefore being negative for cytokeratin (CK) immunostaining (inset), in contrast with adjacent normal liver parenchyma (nl). $(H)$ Colorectal mucinous adenocarcinoma with distended glands (gl) invading the bowel wall. (I) Endometrial carcinoma. Original magnifications: $A, G, H, 40 \times ; F, I, 100 \times ; D, E, 200 \times ; B, C 400 \times$.
In $\sim 60 \%$ of the cases $(19$ of 32 ), the lymphomas were large tumor masses (probably thymic in origin) localized in the anterior mediastinum (Fig. 2A,B), which often involved the heart and lungs and extended into the thoracic soft tissues. In some cases, there was widespread dissemination to abdominal organs (liver, kidney, spleen, and mesenteric lymph nodes) with occasional involvement of mammary glands, gonads, and uterus. Lymphomas of a second type (nodal, 12 of 32; see Fig. 2C), consistently involved massively enlarged spleen and mesenteric lymph nodes and frequently infiltrated additional organs. In two of these cases, lymphoblasts were also present in peripheral blood (leukemia/lymphoma). Some lymphomas were characterized further by immunostaining using antibodies against the $\mathrm{T}$ - and $\mathrm{B}$-cell lineage-specific markers CD3 and B220, respectively. Not unexpectedly, six of six examined mediastinal tumors were of T-cell origin, whereas of eight examined nodal lymphomas, five were of $\mathrm{T}$ - and three of B-cell origin (see Fig. 2B,C, insets).

Of 10 soft tissue sarcomas, two (one hepatic and one splenic) were angiosarcomas arising in a background of hemangiomas (Fig. 2D), whereas the remaining eight were widely metastatic spindle cell sarcomas (Fig. 2E).

The 41 detected primary epithelial tumors included a single colorectal cancer (Fig. 2H), 2 endometrial adenocarcino- 
mas (Fig. 2I), 13 tubulopapillary bronchioloalveolar lung neoplasms (Fig. 2F), 13 liver neoplasms (11 adenomas and 2 frank hepatocellular carcinomas; Fig. 2G), and 12 breast carcinomas described separately below.

To ascertain whether lack or haploinsufficiency of p53 could affect $B r c a 1^{t r / t r}$-associated tumorigenesis, we generated by limited breeding and then monitored eight Brca1 ${ }^{\text {tr }}$

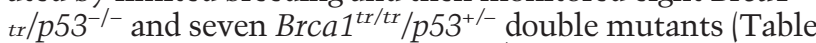
1). The animals carrying the $B r c a 1^{\text {tr/tr }}$ mutation in p53 null background died of lymphomas within a period of $<4 \mathrm{mo}$. Importantly, the $\mathrm{T}_{50}$ for the $B r c a 1^{\text {tr/tr}} / p 53^{-/-}$lymphomas (98 d) was significantly shorter than the $T_{50}$ of the same

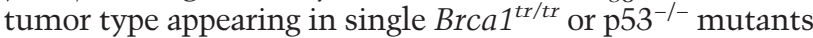
$(P<0.0001)$. Analogous observations made with a few

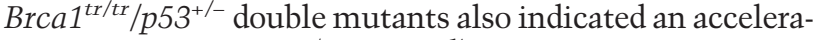
tion in tumorigenesis $\left(\mathrm{T}_{50} 238 \mathrm{~d}\right)$.

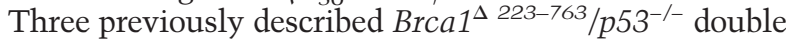
mutants (Cressman et al. 1999) developed lymphomas by the age of $3 \mathrm{mo}$ (one of these animals also developed a hemangiosarcoma). However, because of the double nullizygosity and the fact that lymphomas and sarcomas appear rapidly in $p 53^{-/}$single mutants, a conclusion that the absence of Brcal function had contributed to tumor development could not be reached from these data.

Compared with the situation in humans, the spectrum of tumors developing in Brca1 ${ }^{\text {tr/tr }}$ mice has only partial similarities and is wider, extending to nonepithelial types. Nevertheless, $B R C A 1$, first identified as a breast and ovarian cancer susceptibility gene, could have a broad although not ubiquitous tumor suppressing function (carcinomas at additional sites have been reported in some patients).

\section{Mammary tumors in Brca $1^{\text {tr/tr }}$ mutants}

Twelve mutant animals (11 females and, remarkably, one male) ranging in age between 9 and 23 mo (median of $15 \mathrm{mo}$ ) developed often palpable mammary tumors (Fig. $3 \mathrm{~A}$ ) of strikingly heterogeneous histological patterns (see Table 2).

In general, preneoplastic lesions in mouse mammary glands appear as focal epithelial hyperplasias either in alveoli (hyperplastic alveolar nodules [HANs]) or in terminal ductules (ductal hyperplasias [DHs]). They then can progress to a stage of atypia similar to that of human ductal carcinoma in situ (DCIS), with potential for further development to invasive carcinoma (Medina 1996).

Most of the histologically diverse $B r c a 1^{t r / t r}$ breast carcinomas could not be easily classified as belonging to previously described tumor types. Spontaneous mouse mammary adenocarcinomas, induced in their majority by mouse mammary tumor virus (MMTV), have been classified mainly into types A and B (Dunn 1959). Dunn type A microalveolar tumors consist of single layers of small cuboidal cells surrounding cavities, whereas ductal adenocarcinomas lacking acinar features and appearing as cysts, papillary projections, cords, tubular structures, or solid tumors are grouped in the B category. However, MMTV long terminal repeat-driven transgenic oncogenes mostly generate mammary carcinomas with distinctive patterns. For example, tumors induced by a myc transgene have large cells with pleiomorphic nuclei and dark blue cytoplasm (hematoxylin and eosin staining); ras-associated, usually papillary tumors, have small cells with relatively uniform nuclei and red cytoplasm; and neu-induced solid nodular tumors have cells of in-

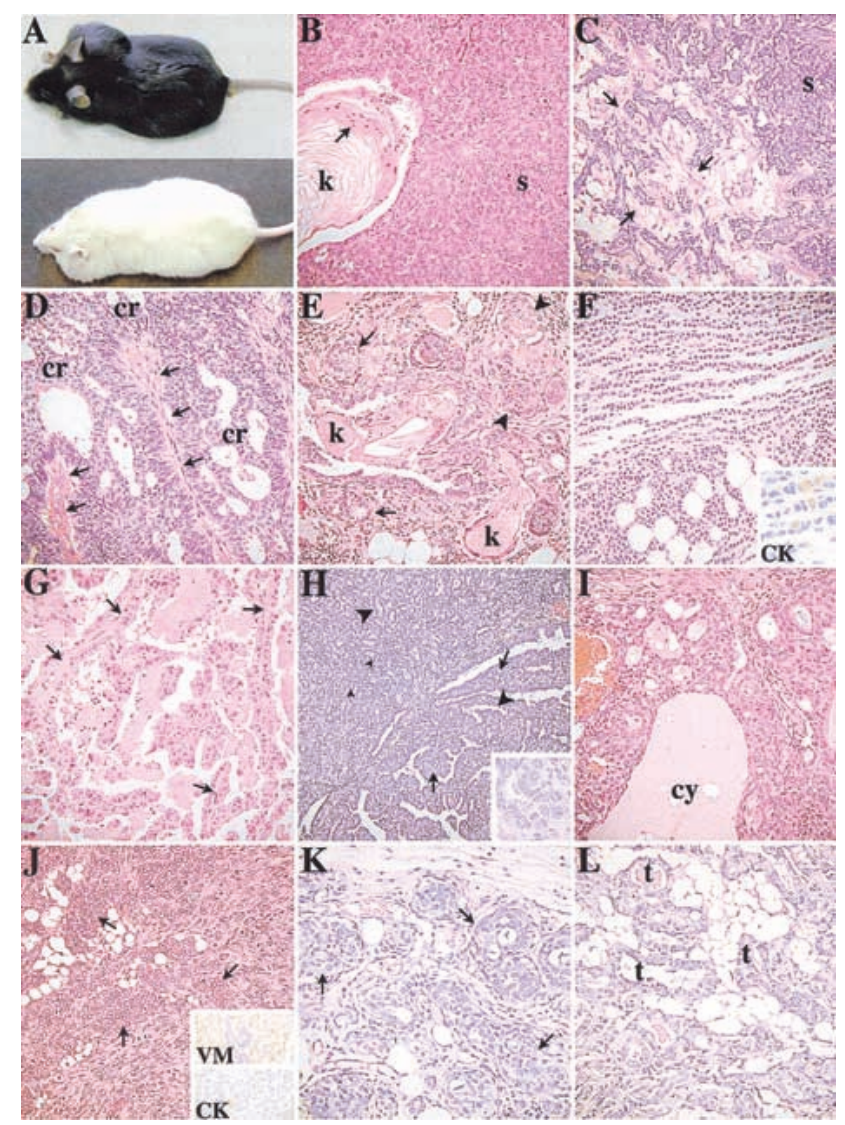

Figure 3. Mammary tumors in Brca1 ${ }^{\text {tr/tr }}$ mutants. (A) Examples of tumor carriers. $(B L)$ Examples of histological sections showing the diverse patterns of breast carcinomas developing in $B r c a 1^{t r / t r}$ mice. $(B)$ Solid tumor (s) with focal squamous differentiation (arrow) forming keratin $(\mathrm{k})$ (case 1; Table 2). (C) Stromal desmoplasia in solid tumor (s). The arrows indicate collagen bands (case 2). (D) Papillary (arrows) and cribriform (cr) architectural pattern (case 3). (E) Adenoacanthoma showing a combination of small glands (arrows) and squamous epithelium (arrowheads) with keratin pearls (k) (case 4). (F) Mammary carcinoma in a male animal (case 5) that is cytokeratin-positive (inset) and shows a characteristic invasion pattern of cells in single files (Indian-file pattern) closely resembling infiltrating lobular human breast carcinoma. $(G)$ Carcinoma composed of numerous papillary fronds with fibrovascular cores (arrows; case 6). (H) Mixed papillary (arrows), glandular (large arrowheads), and acinar (small arrowheads) growth patterns (case 7a). (inset) myc-like cytology (see text). (I) Cystic component (cy) in solid tumor (case 8). (J) Carcinoma with sarcomatous metaplasia (case 10). Poorly formed glands (arrows) retaining cytokeratin expression ( $\mathrm{CK}_{\text {; }}$ inset) are overrun by spindle-like cells expressing vimentin (VM; inset). (K) Atypical epithelial cells of a ductal carcinoma in situ (arrows) are filling and expanding ductules within a hyperplastic alveolar nodule (absence of invasion; case 11). ( $L$ ) Invasive carcinoma forming tubular structures $(t)$ (case 12). Original magnifications $200 \times$ for each panel except $H(100 \times)$.

termediate size with pleiomorphic nuclei and pale pink cytoplasm (see Cardiff et al. 2000). An additional mammary tumor type, adenoacanthoma, is quite common in mice exposed to chemical carcinogens (see, e.g., Medina et al. 1980).

Whereas rare mammary adenocarcinomas developing in p53 nullizygous mice have been described as Dunn type B (see Harvey et al. 1993), only one of 12 Brca1 $^{\text {tr/tr }}$ tumors that we have examined showed a mixture of Dunn type A and B patterns, in combination with myc- 
Table 2. Mammary carcinomas

\begin{tabular}{|c|c|c|c|c|c|c|c|c|c|c|c|}
\hline \multirow[b]{3}{*}{ Case } & \multirow{3}{*}{$\begin{array}{l}\text { Age } \\
\text { (days) }\end{array}$} & \multicolumn{10}{|c|}{ Tumor phenotype } \\
\hline & & \multirow{2}{*}{$\begin{array}{l}\text { Size } \\
(\mathrm{mm})\end{array}$} & \multirow[b]{2}{*}{ Pattern } & \multirow[b]{2}{*}{ Borders } & \multirow{2}{*}{$\begin{array}{l}\text { Nuclear } \\
\text { grade }\end{array}$} & \multicolumn{6}{|c|}{ Immunohistochemistry } \\
\hline & & & & & & ER & PR & neu & cD1 & $\mathrm{p} 21$ & p53 \\
\hline \multicolumn{12}{|c|}{ A. Brcal $1^{\mathrm{tr} / \mathrm{tr}}$} \\
\hline 1 & 280 & 13 & $\begin{array}{l}\text { Solid with few microglandular elements } \\
\text { and focal adenoacanthoma }\end{array}$ & Invasive & Int./high & - & - & - & + & + & + \\
\hline 2 & 334 & 14 & $\begin{array}{l}\text { Peripherally solid and centrally cystic } \\
\text { with stromal desmoplasia }\end{array}$ & $\begin{array}{l}\text { Highly } \\
\text { invasive }\end{array}$ & High & - & - & - & + & + & + \\
\hline 3 & 354 & 12 & Papillary, cribriform, and cystic & $\begin{array}{l}\text { Pushing } \\
\text { margins }\end{array}$ & Int./high & + & + & - & + & + & + \\
\hline 4 & 422 & 1 & Adenoacanthoma & $\begin{array}{l}\text { Pushing } \\
\text { margins }\end{array}$ & Low & \pm & - & \pm & + & + & - \\
\hline 5 & 440 & 8 & $\begin{array}{l}\text { Infiltrating lobular pattern (male } \\
\text { animal) }\end{array}$ & $\begin{array}{l}\text { Highly } \\
\text { invasive }\end{array}$ & Low & - & - & + & \pm & & + \\
\hline 6 & 447 & 7 & Papillary & $\begin{array}{l}\text { Highly } \\
\text { invasive }\end{array}$ & High & \pm & - & + & + & + & + \\
\hline $7 \mathrm{a}$ & 474 & 12 & $\begin{array}{l}\text { Ductal carcinoma: Dunn type B pattern } \\
\text { (tubular, alveolar, papillary, and large } \\
\text { cell ["myc-like" elements) in } \\
\text { combination with Dunn type A } \\
\text { pattern (focal acinar growth); also } \\
\text { multifocal DCIS at tumor borders }\end{array}$ & Invasive & Int./high & \pm & + & + & + & \pm & \pm \\
\hline $7 \mathrm{~b}$ & & & $\begin{array}{l}\text { DCIS emerging from a background of } \\
\text { HAN }\end{array}$ & & & & & & & & \\
\hline 8 & 494 & 8 & $\begin{array}{l}\text { Predominantly cystic in combination } \\
\text { with solid ("neu-like"), glandular, } \\
\text { and focally mucinous patterns }\end{array}$ & Invasive & Intermediate & \pm & + & - & + & + & + \\
\hline 9 & 525 & $<0.5$ & DCIS & & & & & & & & \\
\hline 10 & 589 & 17 & $\begin{array}{l}\text { Poorly differentiated adenocarcinoma } \\
\text { with extensive sarcomatous } \\
\text { metaplasia }\end{array}$ & $\begin{array}{l}\text { Highly } \\
\text { invasive }\end{array}$ & High & - & - & - & + & & +++ \\
\hline 11 & 654 & $<0.5$ & DCIS & & & & & & & & \\
\hline 12 & 680 & 2 & Ductal tubular & Invasive & Intermediate & - & - & - & + & + & + \\
\hline \multicolumn{12}{|c|}{ B. $B r c a 1^{\mathrm{tr} / \mathrm{tr}} / p 53^{+/-}$} \\
\hline 13 & 179 & 16 & Solid and glandular & Invasive & Very high & - & - & - & + & \pm & \pm \\
\hline 14 & 386 & 10 & $\begin{array}{l}\text { Solid and focally cystic with focal } \\
\text { adenoacanthoma }\end{array}$ & Invasive & High & & & & & & \\
\hline
\end{tabular}

Tumors in different mammary glands are described in case $7 \mathrm{a}$ and $\mathrm{b}$. Immunostaining is indicated as positive (+), strongly positive (+++), weakly positive $( \pm)$, or negative $(-)$. When an immunophenotype was not determined, the space is left blank.

(ER) estrogen receptor; (PR) progesterone receptor; (cD1) cyclin D1; (int.) intermediate; (DCIS) ductal carcinoma in situ; (HAN) hyperplastic alveolar nodule.

like cytological features (Fig. 3H; Table 2, case 7a). Overall, the variable histological features of breast tumors in Brca1 ${ }^{\text {tr/tr }}$ mice encompassed a range of growth patterns that included solid, papillary, cribriform, tubular, acinar, mucinous, adenoacanthomatous, and sarcomatous forms (see Fig. 3). Frequently, combinations of these dissimilar patterns were present within a single tumor (Fig. 3D). Some tumors showed stromal desmoplasia (Fig. 3C). The degree of nuclear atypia varied between tumors, whereas the infiltration patterns ranged from circumscribed, expansile lesions with pushing borders to raggedly infiltrating, highly invasive tumors. A single male breast tumor belonged to the latter category and showed uniquely an infiltrative pattern bearing a striking resemblance to human invasive lobular carcinoma (Fig. 3F). In some cases, HAN or foci of DCIS adjacent to tumors were detected (Fig. $3 \mathrm{~K}$ ), but in most animals a background of extensive proliferative breast disease was not observed. The heterogeneity in tumor histopathology was paralleled to some extent with variability of immunophenotypes for estrogen and progesterone receptors and neu (Table 2). On the other hand, all of the breast carcinomas exam- ined were positive for cyclin D1 and $\mathrm{p} 21^{\text {Waf } 1}$ expression and also showed p53 immunoreactivity with only one exception (Table 2).

It is likely that the Brca1 ${ }^{\text {tr/tr }}$ mutation was involved in the development of at least one of two mammary carcinomas detected in $\mathrm{Brca1}^{\text {tr/tr}} /{\mathrm{p} 53^{+/-}}$double mutants (Table $2)$, because the histological pattern was not observed previously in rare mouse breast tumors associated with haploinsufficiency or loss of p53 (Harvey et al. 1993), whereas the latency was only 6 mo $\left(p 53^{+/-}\right.$mice do not develop tumors of any kind before the age of $11 \mathrm{mo}$; for review, see Attardi and Jacks 1999).

Histopathologically diverse breast carcinomas, including tubular and solid adenocarcinomas, were detected previously by microscopic examination of mammary tissue in five of 23 conditional mouse mutants between 10 and 13 mo of age, after Cre-mediated deletion of Brca1 exon 11 specifically in mammary epithelial cells (Xu et al. 1999). However, in contrast with these microscopic carcinomas, eight of 12 mammary tumors that were encountered in $\mathrm{Brca}^{\text {tr/tr }}$ mice were large, palpable masses. In addition, other phenotypic differences were noted that 
can be potentially attributed to structural dissimilarities between the conditional and Brca1 ${ }^{\text {tr/tr }}$ mutations. Thus, ablation of the Brca1 exon 11 resulted in mammary gland underdevelopment, increased apoptosis, and abnormalities in involution (Xu et al. 1999), whereas the mammary glands of Brca1 $1^{\text {tr/tr }}$ mutants, if not affected by tumors, were normal. In both types of mutants, however, reduction of p53 dosage had a similar impact in accelerating progression.

How do cellular changes elicited by the absence of Brcal function participate in tumor pathogenesis? Although this key mechanistic question continues to remain open, the genetic evidence that we have provided is compatible with a view of opportunistic participation in tumorigenesis. Thus, we speculate that the pre-existing Brca1 $^{\text {tr/tr }}$ lesion remains dormant until a randomly and progressively occurring combinatorial engagement of other deranged pathways seizes by chance the lack of Brcal action as a fitting component in triggering progression toward full-fledged malignancy. Perhaps, the histologic heterogeneity that we have observed in mammary tumors reflects the potential of a Brcal lesion to become a late participant in variable combinatorial sets of tumorigenic pathways.

\section{Materials and methods}

Targeted mutagenesis

The targeting vector (Fig. 1A) consisted of a cloned 8.5-kb 129/Sv DNA fragment carrying exons 9-12 of Brca1 that was interrupted by the insertion of a dual selection marker cassette ( $t k-n e o)$ flanked by loxP sites into a unique NheI site of exon 11 (position 2882 of the mouse cDNA sequence; GenBank accession no. U32446). A diphtheria toxin A gene cassette was included in the construct as a negative selection marker against random integration. To avoid potential transcriptional interference, we electroporated cells of independently targeted 129/Sv ES cell clones with a Pgk-cre plasmid for transient expression of the recombinase, to excise the loxP-flanked selection marker cassette. Gancyclovirresistant clones analyzed for successful deletion were then used for generation of male chimeras by standard methods, which were crossed with C57BL/6J (B6) females. $\mathrm{F}_{1}$ heterozygous progeny $(129 \times \mathrm{B} 6)$ were intercrossed; backcrossed with wild-type partners of either the B6 or the 129 parental strain; and also outcrossed with MF1 mice. The p53 mutant mice used in some of the experiments were obtained from the Jackson Laboratories.

Molecular and biochemical analyses

For genotyping by Southern analysis, DNA was prepared from yolk sacs of embryos or the tail tip of 10-day-old mice. Northern blots were hybridized with cDNA probes for Brca1 (exons 16-24), p21 Waf1, and Gapd (loading control).

Two antibodies raised against GST fusion proteins representing different regions of murine Brcal were used for protein analysis by standard protocols: the mouse monoclonal antibody GH118 (raised against residues 1336-1821) and the rabbit polyclonal antibody B28 (raised against residues $1-231$ ).

\section{Histological analysis}

Mice showing overt pathological signs were killed and underwent autopsy. All major organs were processed for histology. Paraffin blocks were sectioned at $5 \mu \mathrm{m}$ and stained with hematoxylin and eosin. Immunophenotyping was performed with primary antibodies against estrogen receptor, progesterone receptor, and $\mathrm{p} 21^{\text {waf } 1}$ (Santa Cruz Biotechnology); c-neu and p53 (Oncogene Research Products); cyclin D1 (Novocastra Laboratories); B220 (Pharmingen); CD3 (Dako); cytokeratin (Chemicon); and vimentin (Research Diagnostics).

\section{Acknowledgments}

We thank Lejuan Chatman, Qiong Li, and Mian Su for expert technical assistance. This work was supported by NCI Grant P01 CA75553 (Project
3) to A.E. Seed funding was provided by Grant 9625 to A.E. from the Susan G. Komen Breast Cancer Foundation. T.L. was partially supported by a Career Development Award provided by Grant R21 CA66224 to the Herbert Irving Comprehensive Cancer Center of the Columbia Presbyterial Medical Center.

The publication costs of this article were defrayed in part by payment of page charges. This article must therefore be hereby marked "advertisement" in accordance with 18 USC section 1734 solely to indicate this fact.

\section{References}

Attardi, L.D. and Jacks, T. 1999. The role of p53 in tumour suppression: Lessons from mouse models. Cell. Mol. Life Sci. 55: 48-63.

Boyd, M., Harris, F., McFarlane, R., Davidson, H.R., and Black, D.M. 1995. A human BRCA1 gene knockout. Nature 375: 541-542.

Cardiff, R.D., Anver, M.R., Gusterson, B.A., Hennighausen, L., Jensen, R.A., Merino, M.J., Rehm, S., Russo, J., Tavassoli, F.A., Wakefield, L.M., et al. 2000. The mammary pathology of genetically engineered mice: The consensus report and recommendations from the Annapolis meeting. Oncogene 19: 968-988.

Cressman, V.L., Backlund, D.C., Avrutskaya, A.V., Leadon, S.A., Godfrey, V., and Koller, B.H. 1999. Growth retardation, DNA repair defects, and lack of spermatogenesis in BRCA1deficient mice. Mol. Cell. Biol. 19: 7061-7075.

Deng, C.-X. and Scott, F. 2000. Role of the tumor suppressor gene Brcal in genetic stability and mammary gland tumor formation. Oncogene 19: 1059-1064.

Dunn, T.B. 1959. Morphology of mammary tumors in mice. In The physiopathology of cancer. (ed. F. Homburger), pp. 3884. Hoeber-Harper, New York.

Hakem, R., de la Pompa, J.L., Sirard, C., Mo, R., Woo, M. Hakem, A., Wakeham, A., Potter, J., Reitmair, A., Billia, F., et al. 1996. The tumor suppressor gene Brcal is required for embryonic cellular proliferation in the mouse. Cell 85: 1009-1023.

Harvey, M., McArthur, M.J., Montgomery, C.A., Bradley, A., and Donehower, L.A. 1993. Genetic background alters the spectrum of tumors that develop in p53-deficient mice. FASEB I. 7: 938-943.

Medina, D. 1996. Preneoplasia in mammary tumorigenesis. In Mammary tumor cell cycle, differentiation, and metastasis. (eds. R.B. Dickson and M.E. Lippman), pp. 37-69. Kluwer Academic Publishers, Boston.

Medina, D., Butel, J.S., Socher, S.H., and Miller, F.L. 1980. Mammary tumorigenesis in 7,12-dimethybenzanthracene-treated $\mathrm{C} 57 \mathrm{BL} \times \mathrm{DBA} / 2 \mathrm{f}$ F1 mice. Cancer Res. 40: 368-373.

Mixon, M., Kittrell, F., and Medina, D. 2000. Expression of Brca1 and splice variant Brca1s11 RNA levels in mouse mammary gland during normal development and tumorigenesis. Oncogene 19: 5237-5243.

Monteiro, A.N. 2000. BRCA1: Exploring the links to transcription. Trends Biochem. Sci. 25: 469-474.

Scully, R. and Livingston, D.M. 2000. In search of the tumoursuppressor functions of BRCA1 and BRCA2. Nature 408: 429-432.

Welcsh, P.L., Owens, K.N., and King, M.C. 2000. Insights into the functions of BRCA1 and BRCA2. Trends Genet. 16: 6974.

Xu, X., Wagner, K.U., Larson, D., Weaver, Z., Li, C., Ried, T. Hennighausen, L., Wynshaw-Boris, A., and Deng, C.-X. 1999. Conditional mutation of Brca1 in mammary epithelial cells results in blunted ductal morphogenesis and tumour formation. Nat. Genet. 22: 37-43. 


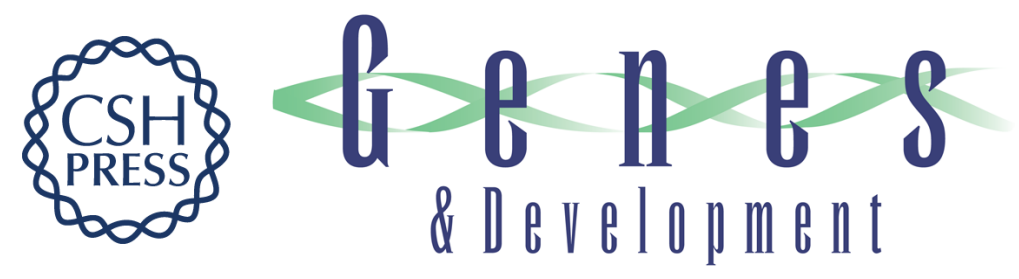

\section{Tumorigenesis in mice carrying a truncating Brca1 mutation}

Thomas Ludwig, Peter Fisher, Shridar Ganesan, et al.

Genes Dev. 2001, 15:

Access the most recent version at doi:10.1101/gad.879201

References This article cites 13 articles, 2 of which can be accessed free at: http://genesdev.cshlp.org/content/15/10/1188.full.html\#ref-list-1

License

Email Alerting Receive free email alerts when new articles cite this article - sign up in the box at the top Service right corner of the article or click here.

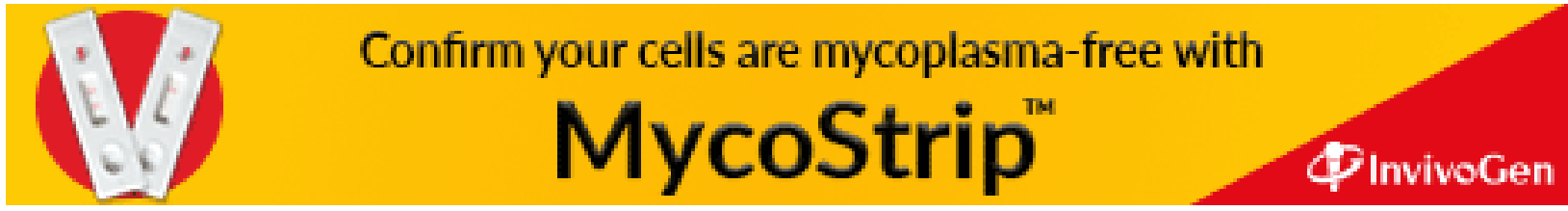

